\title{
BARTHES, LUCIA E EU: CONVERSA EM TORNO DOS CAMINHOS
}

Lucia Castello Branco

Entrevista por: João Rocha*

* jarochabr@yahoo.com.br

Professor e Doutor em Teoria da Literatura e Literatura Comparada pela UFMG.

A noite já começava a avançar, quando cheguei à casa da Avenida Brasil, chamada Cas'a'screver. Já estava atrasado, pois marquei nosso encontro para o fim da tarde e, quando subi as escadas da casa, a noite já se iniciava. Lá dentro, Lucia Castello Branco já me esperava. Lembro que ela estava vestida de branco e pensei, imediatamente, nesta frase de Maria Gabriela Llansol: "o devir de cada um está no som do seu nome”. Pedi desculpa pelo atraso e ela disse que não havia problema. Lucia, então, me conduziu para a sala onde noss conversa se daria e me disse que aquele espaço seria inaugurado dentro de alguns dias e receberia o nome de (Pausa)Ler. O que nos reunia, ali, naquele dia, era a alegria da companhia, pois estávamos eu, Lucia e, silenciosa e discretamente, Roland Barthes, em torno do qual nossa conversa se teceria.

O que se segue é a transcrição da alegria de um encontro

que passou por caminhos transitáveis, como o é uma cord bamba: os deslocamentos entre o professor e o escritor, a psicanálise, a questão da universidade, o exílio, a casa, a comunidade, os biografemas... Caminhos que se sustentam sob a forma de tensões e atritos, como a colocação de uma frase nominal que coloca lado a lado três nomes próprios. Uma frase muito próxima, muito distante, muito perigosa, pois se encontra no litoral do que escreveu Rimbaud, "eu é um outro", mas é somente com ela que poderia responder a alguém sobre o que conversamos ali, nas paredes daquela casa, naquela sexta-feira de outubro. Eis a frase absurda que guarda os caminhos da conversa que se segue: "Barthes, Lucia e eu". 
JOÃo ROCHA: LUCIA, VOCÊ JÁ DISSE, ALGUMAS VEZES, QUE O PRIMEIRO TEXTO QUE OS ALUNOS DEVERIAM LER, QUANDO ENTRAM PARA A FACULDADE DE LETRAS, É AULA, DE ROLAND BARTHES. GOSTARIA QUE COMEÇÁSSEMOS COM VOCÊ DIZENDO POR QUE.

Lucia Castello Branco: Para começar, porque aquilo é uma aula e uma aula inaugural. Ele é um texto da década de 70 e tem uma importância histórica para os estudos barthesianos. Barthes, nesse momento, só falava de escritura Ele tinha abandonado o termo literatura, desde que ele tinha, digamos assim, inventado ou descoberto essa noção de escritura, que é a escrita do escritor. Diferentemente de Blanchot, que nunca o abandonou. Não interessava mais a ele pensar a literatura como uma essência. Barthes retorna a ela contaminado pela escritura. Ele faz as pazes com a literatura nesse texto. Essa é a leitura que a Leyla PerroneMoisés faz também. Eu a vi apresentando uma leitura da Aula, na década de 80, em um congresso da ABRALIC, e deu um quebra-pau danado depois. Era a época do princípio da discussão da primeira noção, digamos, da pós-modernidade. Então, acharam que ela estava fazendo uma leitura muito essencialista do Barthes. Mas eu concordo com ela: Barthes retorna à literatura. Portanto, em primeiro lugar, esse texto deve ser conhecido, porque, dentro da obra de Barthes, ele ocupa um lugar super importante, que é o de um retorno à literatura. Depois, porque é uma aula e é uma aula muito importante, pois ele é convidado a ocupar um importante lugar de saber, no Collège de France, e ele nomeia Foucault como quem o convidou.

Barthes e Foucault tinham uma amizade e uma diferença. Em alguns momentos, Barthes era criticado por Foucault como aquele sujeito que não se assumia, não ia à passeata dos homossexuais... Vamos pensar que Foucault sempre assumiu essa questão e a assumiu publicamente. Ele foi um dos primeiros intelectuais, de que nós temos notícia, que morreu de Aids, em uma época em que a Aids parecia ser alguma coisa do reduto dos homossexuais... E Barthes era sempre aquele sujeito discreto. Então, eu acho que ele aceita esse lugar no Collège de France e dá uma resposta a Foucault, quando formula que a literatura é o saber que deveria permanecer e o engajamento do escritor é o engajamento com a própria língua. Ele está falando da posição dele.

Depois, Barthes diz que é um sujeito incerto. Acho bonito, quando ele começa dizendo isso, pois, pensando que ele está dialogando com Foucault, há uma conotação importante porque ele não tinha título, João. Barthes era um cara sem mestrado, sem doutorado... Um notório saber.

E o último motivo que me faz dizer que os alunos deviam ler a Aula é que Barthes é um super professor, que nunca deixou de ser escritor, sendo professor. Talvez seja 
em uma aula dele - nos seminários também - que você o vê se colocar como professor e escritor, juntos. Ele consegue reunir essas duas coisas. Para a professora que eu sou, ou que eu acredito ter sido, já que eu estou, digamos assim, encerrando uma carreira dentro da Faculdade de Letras, Barthes é a voz.

Sempre houve esta divisão, de alguma forma, nas Letras: Fulano é mais acadêmico... Esse aqui é mais poeta. E Barthes reúne essas duas coisas. Ele é o escritor-professor. Ele mesmo faz a diferença. Ele diz que um professor é aquele que termina suas frases e o escritor é aquele que não termina.

\section{JR: ELE É UM PROFESSOR QUE TERMINA COM RETICÊNCIAS. .}

LCB: É. E ele mesmo ensina, para mim, que um professor pode não terminar as suas frases. Eu aprendi isso com ele. Hoje mesmo, eu dei uma aula, e pensei: o primeiro pé dela está em Barthes e o segundo em Llansol. Eu tinha todo um esquema sobre aquele texto do Gérard Pommier, "Até onde as palavras podem nos transportar". Todo um esquema dessa aula, porque na graduação esse assunto é difícil, sobretudo para um curso que está começando. Eu comecei a aula e uma aluna fez a seguinte intervenção: "Isso não tem a ver com o 'eu mesmo'?”. E eu falei: “Quem é o 'eu mesmo'?". Aí, a aula se deslocou para a questão do je e do moi e do sujeito do inconsciente. E eu fiz uma enorme digressão contando, publicamente, essa história que eu te contei do Caetano ${ }^{1}$, comentando que eu queria dizer para ele que eu era eu mesma. Mas quando eu dizia que eu era eu mesma, eu pensava: "Como assim, eu sou eu mesma?" (risos). Ou seja, a aula, que era sobre até onde as palavras podem nos transportar, foi uma aula sobre o transporte, porque a aluna disse: "Essa questão do gozo não tem a ver com o 'eu mesma'? Com o sujeito?”. E aí a aula virou outra coisa! Eu disse, bom gente, eu apenas introduzi esse texto e vocês leem para a próxima aula. Depois, eu me dei conta de que a aula foi guiada por um mecanismo, um método, digamos, ou uma autorização que Barthes nos dá, que é a autorização da digressão. Você lembra quando ele fala disso? Que a digressão é o grande movimento do texto... grande movimento que o texto pode fazer. Você aprende que a digressão é parte daquele contorno. E você só se permite isso, se você conseguir ter uma abertura, que eu acho que a psicanálise dá. Há, para mim, um Barthes antes e depois da psicanálise. O Barthes depois da psicanálise é um Barthes muito mais autorizado a ser... Barthes.

JR: HOJE, EM UMA AULA, UMA ALUNA ESTAVA FALANDO, REPETIDAMENTE, DO REAL LACANIANO. ELA DIZIA OUE, DEPOIS DE LACAN, NÃO HÁ COMO FALAR DE REAL SEM O CONTEXTUALIZAR. E ESSE REAL ELA O ESCREVIA COM LETRA MAIÚSCULA. E EU PERGUNTEI SE ELA
1. Nesse dia, antes de começarmos a gravação desta entrevista, Lucia Castello Branco me contou que, uma vez, Caetano Veloso Ihe enviou um email, mas, por razões desconhecidas, ele chegou para uma homônima que respondeu dizendo que, embora tivesse o mesmo nome, não era a Lucia Castello Branco ao qual o email era destinado. Até tudo se esclarecer, houve uma certa confusão e essa história rendeu boas gargalhadas. 
2. Escola que Maria Gabriela Llansol coordenou, junto com outros amigos, na Bélgica, durante o período em que estava exilada.
SABIA QUE O REAL, COM MAIUUSCULA, ERA DO ROLAND BARTHES, EM AULA, OBVIAMENTE INFLUENCIADO PELA PSICANÁLISE LACANIANA.

LCB: Sim, é ele quem vai cunhar essa escrita.

JR: LUCIA, VOCÊ FALANDO DE DIGRESSÃO E EU AGORA VOU TENTAR ELABORAR UMA. QUANDO VOCÊ DIZIA DA FUNÇÃO DO PROFESSOR, MÉTODO DO PROFESSOR, VOCÊ FALOU DA VOZ. PARECE LÓGICO, MAS EU NUNCA TINHA ME ATENTADO PARA A VOZ DO PROFESSOR. E EU LEMBREI OUE SEU ÚLTIMO LIVRO, MARIA LUA DA MINHA ESCURIDAO, UM LIVRO INFANTO-JUVENIL, VOCÊ TAMBÉM LANÇOU EM ÁUDIO.

LCB: Foi. Inclusive, o lançamento do livro em áudio atrapalhou o e-book demais, porque muita gente ouviu e já ficou satisfeito e achava que não precisava ver o livro (risos). Eu pensei: "Gente, o negócio ficou bom mesmo!" (risos). Muita gente tem preguiça de baixar, de comprar...

JR: O QUE EU QUERO TE PERGUNTAR É ISTO: SE ESSA JUNÇÃO DO PROFESSOR E DO POETA, DO PROFESSOR E DO ESCRITOR, NÃO SE DARIA TAMBÉM NO PONTO DO GRÃO DA VOZ, OU SEJA, POR ALGO QUE É DO CAMPO DA VOZ.

LCB: Eu acho que sim. Há aquela expressão sobre a sublimação, aquele teoremazinho que Lacan constrói: a sublimação seria elevar o objeto à dignidade da coisa. Eu acho que Barthes faz isso com o professor. Ele eleva o objeto. Porque o professor é uma coisa tão degradada, não é, João? É uma coisa tão degradada! Quer dizer, não tem nobreza, hoje, no lugar do professor. E Barthes, eu acho, conseguiu elevar isso que é enorme na função do professor, essa coisa do mestre, à dignidade. Porque ou o mestre é uma bobagem... Ou é o discurso do mestre, como se fala na psicanálise... Aquele que impõe um saber... E Barthes vai trazer aquilo que aparece naquele texto do Peter Pal Pelbart: a função do professor é reconciliar o aluno com sua própria solidão. Isso não é lindo? E eu acho que Barthes faz isso. Ele, e essa é a impressão que eu tenho, quando estava ali dando uma aula, reconciliava-se com a própria solidão. Então, é muito doido, porque talvez o que eu tenha mais aprendido com Barthes, que, para mim, é, acima de tudo, um grande escritor, foi a dar aula.

\section{JR: ISSO É BONITO.}

LCB: Isso é sensacional! Sinceramente, eu aprendi a dar aula com duas pessoas: Barthes e Llansol. Barthes eu posso dizer que eu o vi, o ouvi dando aula, na medida em que eu li, por exemplo, a Aula, os seminários deles etc. Mas Llansol eu nunca vi... Nem ela fazendo um ateliê na École da la Rue de Namur ${ }^{2}$. Contudo, Llansol, sendo a escritora que ela é, da maneira que ela é, me autorizou a ser a professora que eu sou. Isso é muito doido, mas é!

Quando eu encontrei a Llansol, em 1992, eu era professora da Faculdade de Letras desde 1984. Então, eu tinha
EM TESE
BELO HORIZONTE
v. 21
N. 2
MAIO-AGO. 2015

CASTELLO BRANCO; ROCHA. Barthes, Lucia e eu: conversa em torno [.. . ]

213-230 
oito anos como professora da Letras. Eu estava muito cansada de dar aula e ficava triste quando ia trabalhar, pois eu pensava assim: "Eu vou ter que fazer isso a minha vida in teira! Trinta anos fazendo isso! Como é possível?!”. Porque nós recebíamos as ementas e eu achava que dar aula era segui-las... Eu achava que tinha que fazer aquilo daquele jeito. E aí, a primeira alegria, quando eu encontrei o texto da Llansol, foi pensar assim: "Gente, eu vou poder me ocupar disso a vida inteira!”. Então, já havia melhorado a situação.

Quando nos encontramos, eu falei com ela que eu estava muito esgotada de dar aula... Que às vezes eu achava que dar aula me roubava das outras coisas... De ser escritora.. De escrever, pesquisar... Foi um encontro que a gente teve, muito interessante. A gente se despediu na estação de Sintra, eu, voltando para Lisboa, e me lembro que a última frase dela para mim foi assim: "Mas é uma atividade muito importante. É muito importante”. E aí, ela foi embora. E eu, na hora que entrei no trem, tive uma espécie de visão, muito doida, como se ela estivesse subindo uma montanha. Sabe, a visão de uma ermitã? Aquela pessoa com um cajado subindo uma montanha. Ela falou essa frase que ficou para mim. Logo depois, teve a Carta ao legente ${ }^{3}$, que ela escreve para Lucia Castello Branco e seus alunos. Então, ela me deu um lugar. Como uma pessoa que diz: "Toma essa missão e sustenta isso, até o fim".
JR: MUITO INTERESSANTE VOCÊ LEVANTAR ESSA QUESTÃO DAS EMENTAS E DA PRISÃO QUE PODE SER, POR VEZES, SEGUI-LAS. ISSO POROUE UMA DAS MINHAS QUESTÕES, HOJE EM DIA, É JUSTAMENTE ESSA... É UM CONFLITO.

LCB: Eu levantava para dar aula numa tristeza, João, você não acredita. Aí, chegava lá e eu melhorava, porque lá a coisa acontecia. Até o dia que eu cheguei para os alunos e disse: "Gente, eu odeio dar aula". Os alunos olharam para mim com cada olho! (risos). "Eu acho insuportável isso... Eu me arrasto até aqui”, eu falei. Era uma coisa assim: eu podia ter sido aquelas professoras que entram em depressão e ficam pedindo licença para o resto da vida. De tanto que aquilo era insuportável. Para mim, como professora, foi assim: um antes e depois de encontrar Llansol e de reencontrar Barthes.

Logo depois que eu encontrei a Llansol, voltei para o Brasil e, nessa época, eu tinha dois alunos, que foram meus alunos de iniciação científica, Paulo de Andrade e Sérgio Antônio Silva. Paulo é poeta e Sérgio, escritor e editor. Ambos, hoje, são professores. Eles me procuraram para orientá-los em um projeto de iniciação científica, pois estavam com a seguinte questão: eles tinham feito uma prova para um professor da Faculdade de Letras e esse professor tinha corrigido a prova deles - eles escrevem muito bem, sempre escreveram, desde novinhos - e tinha dado A para os dois, com a nota 90 , ao invés de 100 , colocando o seguinte comentário na prova: "Mas o que é isso? Crítica barthesiana?". E eles
3. LLANSOL, Maria Gabriela. Carta ao legente. O fio de água do texto. 2011. Disponível em: $<$ https://fiodeaguadotexto. wordpress.com/2011/06/07/cartaao-legente-2/>. Acesso em: 02 nov. 2015
EM TESE
BELO HORIZONTE
v. 21
N. 2
MAIO-AGO. 2015

CASTELLO BRANCO; ROCHA. Barthes, Lucia e eu: conversa em torno [.. . ]

p. 213-230 
ficaram muito tocados, pensando porque tinham recebido essa crítica. Eles nem sabiam, nem conheciam ainda Roland Barthes. Então, queriam entender o porquê daquela pecha de bartesianos. Aí, decidiram estudar Roland Barthes para saber o que era isso, crítica barthesiana. $\mathrm{O}$ primeiro projeto de iniciação científica deles foi sobre Roland Barthes, por causa da crítica que eles receberam desse professor. E são, justamente, esses dois, mais Cristiano [Florentino], que Llansol cita naquele texto "O sonho de que temos a linguagem”. Uma vez, eles mandaram uns trabalhos para ela e ela os respondeu nesse texto, dizendo: "Só posso dizer que são textos fortes, os deles abertos ao meu. Como não abrir o meu texto ao deles?”. E aí, ela começa a citar a prova do Sérgio.. Quer dizer, uma escritora, como Maria Gabriela Llansol, tinha recebido dos alunos trabalhos que nem eram sobre ela porque o do Paulinho era sobre Cesário Verde; o do Sérgio era sobre Amar um cão, mas misturado com Lacan e não sei mais o quê; tinha trabalhos "acadêmicos", digamos... E tinha se aberto aos textos deles, reconhecendo, neles, textos de escritores. Logo em seguida eu pensei: "Essa Llansol tem a ver com Roland Barthes".

Como Llansol nunca o citou, eu acho, em algum texto dela consegui com que a Rebecca [Cortez de Paula Carneiro], minha orientanda nessa época, fizesse uma entrevista com Llansol e uma das perguntas que a gente elaborou era sobre sua relação com Roland Barthes. E ela falou: "Ele é meu livro de cabeceira”. Eu nem sabia que ela ia responder isso, mas eu intuí que tinha alguma coisa nela que tinha a ver com Roland Barthes. Depois que eu fiquei sabendo, então, que a única atividade que Llansol teve, além de ser escritora, de escrever a vida inteira, foi coordenar uma escola e que ela, mais do que isso, relaciona o início da textualidade, que é O livro das comunidades, à experiência da École de la rue de Namur e ao fato de ter trazido uma criança autista à fala, percebi que ela junta, na textualidade - isso é uma tese que ainda deve ser feita sobre Llansol, não é? - a educação - a pedagogia, vamos pensar assim -, a psicanálise - pois ela trouxe uma criança autista à fala, e ela diz: "Quando eu conduzi uma psicanálise" - e a textualidade.

Então, a textualidade tem a ver com isso. Isso é sensacional! E eu acho que Barthes fez isso na carreira dele. Ele é esse sujeito impuro... Esse sujeito incerto... Que escrevia sobre moda... Que escrevia para jornal... Que ficava falando dos gostos peculiares dele por uma caneta, por um papel, por um não sei quê... Quer dizer, isso eu também acho genial, porque ele desierarquizou os temas da crítica literária. Llansol também tem a ver com isso. Ela é aquela que escreve até sobre as hemorroidas, não é? A vaca louca... Isso entra no texto dela e tal... Então Barthes desierarquiza tudo. Ele pode ser tudo isso, mas uma coisa que eu acho que ele fez, 
elevando o objeto à dignidade da coisa, foi juntar a prática do professor à prática do escritor e à prática psicanalítica, pois mesmo ele, não sendo um psicanalista, foi completamente atravessado pela psicanálise. E ele leva a psicanálise para os textos dele.

\section{JR: VOCÊ SABE SE ELE FEZ ANÁLISE?}

LCB: Sei. Ele procurou análise com Lacan - isso está em alguma biografia do Lacan ou dele, já não me lembro mais - e Lacan recusou, o que eu acho super curioso, dizendo assim: "Continue escrevendo as suas coisas que está ótimo”. Não acho que ele recusou porque Barthes era um escritor, porque Lacan atendia outros escritores... Sollers, por exemplo. Ele recusou o Barthes. Mas parece que eu li, se não me engano, em uma dessas biografias, não sei se é a da Leda Tenório, que ele foi fazer análise, então, com outra pessoa.

De fato, ele é completamente atravessado pela experiência do inconsciente. O texto dele é completamente atravessado por conceitos da psicanálise. O prazer do texto é completamente atravessado... Há horas em que eu acho que ele é quase citação do "Além do princípio do prazer", do Freud... O conceito de Real, como você lembrou... A Aula, para mim é isso... E se a gente for pensar, na época do Barthes, quem era o sujeito que estava "dando aula" para multidões em Paris? Era Lacan
Shoshana Felman vai ler o desejo do analista, de Lacan, completamente ligado ao desejo de transmissão. Lacan, depois de expulso, depois de ser sabotado pelos amigos etc., não podia mais ser analista didata. Ele continuou dando os seminários dele. Isso ele não pára de fazer. Mesmo já velho, já no final da vida, não pára de fazer essa coisa do seminário público..

\section{JR: ... DA TRANSMISSÃO...}

LCB: Isso. Vinha quem quisesse, entrava quem quisesse e lá estava Lacan. Dizem que era uma coisa insuportável, disse Shoshana, porque todo mundo fumava, nessa época, dentro do ambiente... Tinha que chegar umas quatro horas antes para ter uma cadeira para sentar. E Lacan com aquela multidão... Ele adorava. Ficava pensando alto... Falando aquelas coisas... Barthes também, não é? Multidões iam assistir ao Barthes.

JR: EU ESTAVA PENSANDO... QUANDO VOCÊ REÚNE A FIGURA DO PROFESSOR, DO ESCRITOR E DO PSICANALISTA, REMETE-ME À NOÇÃO BARTHESIANA DE BIOGRAFEMA, MUITO TRABALHADA POR VOCÊ, E TAMBÉM ÀS PRÁTICAS DA LETRA, QUE VOCÊ JÁ FAZ HÁ MUITO TEMPO E OUE, DE ALGUMA MANEIRA, TOCAM ESSES TRÊS LUGARES...

LCB: A prática da letra, que você me acompanhou por muito tempo e acompanha até hoje, não é aula, mas é aula também, em certo sentido, se a gente entende "aula" no sentido lá da 
“Leçon", de Barthes. Nesse caso, você não está ensinando nada para o sujeito, mas se a gente entende que também em uma aula não se ensina nada, a única coisa que Barthes te ensina é o que todos os grandes mestres ensinam... Um grande pintor, um grande escritor ensinam a você a encontrar uma coisa tão cert quanto esta. Leyla Perrone fala muito lindo sobre isso naquele texto "Lição de casa", no fim da Aula. Ela diz assim: "Ninguém ensina nada para o outro... Você não pode mais fazer como Barthes... Porque viraria uma idiotice fazer como Roland Barthes... Encontra a sua coisa tão certa quanto esta." Isso não é a lição do Lacan? "Se vocês quiserem sejam lacanianos, quanto a mim sou freudiano. Sejam como eu, não me imitem." Porque o que se transmite é um estilo. É a única coisa que se transmite.

JR: A GENTE PODERIA PENSAR QUE, NESSE TIPO DE AULA, O QUE TAMBÉM SE TRANSMITE É UM BIOGRAFEMA?

LCB: É. Vamos pensar: o que é um estilo? É um biografema, a única coisa que se transmite... Um, dois, três... E o mais legal é isto: o biografema, de quem é? A quem pertence um biografema?

\section{JR: ISSO ERA UMA OUTRA PERGUNTA...}

LCB: Vamos pensar na palavra que ele cria: bio, vida, e grafe$m a$, letra. O biografema é: a letra de uma vida. Mas, pensando em uma vida, no sentido de Deleuze, naquele texto ${ }^{4}$ que você e o Érick [Gontijo Costa] traduziram, o que é uma vida, senão uma imanência pura? Pode-se falar de "uma vida" em um sujeito só no momento do moribundo. Nesse momento, fala-se de uma vida. Ela é a mais absoluta singularidade e a mais absoluta impessoalidade. Eu acho que é isso que acontece, quando um sujeito consegue ser um professor como Roland Barthes. Imagina aquela aula cheia de digressões, cheia de biografemas... Ele conta do Foucault... Conta que é um sujeito impuro... Incerto... Agradece pela alegria, pois a honra pode ser imerecida, mas a alegria nunca o é... Quer dizer, ele está falando um monte de coisas dele, entregando um monte de biografemas para gente, mas esses biografemas só serão biografemas, de fato, se aquele ouvinte, ou, no caso, o leitor que estiver lendo aquele texto, pescar aquilo. Os biografemas não são como cinzas lançadas ao vento que têm que tocar um corpo futuro fadado à mesma dispersão? Então, se não tocar o corpo daquele aluno, nada se deu, não é? E, para que toque o corpo daquele aluno, deve haver alguma coisa nele que recolha o biografema. Porque o biografema tem a ver com o legente ${ }^{5}$, João. O legente, o legere, é aquele que colhe, "alguém que colhe a flor que falta para que se acalme a minha perturbação pessoal”, escreve Llansol na Carta ao legente. Então, é aquele que colhe. E você vai colher um biografema, o fulano de tal colhe outro, e tem gente que não vai colher nenhum. Ele só se dá na colheita (risos).
5. Forma que a escritora Maria Gabriela Llansol chama o "leitor" em sua obra.

4. Lucia Castello Branco se refere ao texto, de Deleuze, "Imanência: uma vida". 
E a colheita só se dá, se há um legente ou um espectador... Alguém que receba aquilo ali.

JR: POR ISSO É TÃO INÚTIL AOUELA POLÊMICA COM RELAÇÃO AOS DIREITOS AUTORAIS DAS BIOGRAFIAS... POROUE, NELA, TEM-SE A IDEIA DE QUE A VIDA PERTENCE A ALGUÉM...

LCB: Eu me lembro de que uma vez, discutindo isso com o Eduardo Vidal, ele falou assim: "Como alguém pode pensar que a vida lhe pertence?”. E eu, rapidamente, falei: “E como alguém pode pensar, então, que a escrita lhe pertence?" Pensando aí na vida escrita. .

JR: E ESSA, FAZENDO UMA DIGRESSÃO, FOI A QUESTÃO DA SUA ALUNA ESTA MANHÃ. E ELA TEM A VER TAMBÉM COM OUTRA COISA. EU LI MUITO ROLAND BARTHES COM VOCÊ, EM AULAS SUAS, E EU ME LEMBRO DE OUE, NA ÚLTIMA DISCIPLINA SUA QUE EU SEGUI, NÓS LEMOS MUITO BARTHES, SOBRETUDO, A PREPARAÇÃOO DO ROMANCE, SEU ÚLTIMO SEMINÁRIO. NESSA "AULA", DIGAMO ASSIM, BARTHES, PARA FALAR DA PREPARAÇAO DO ROMANCE, COMEÇA NA POESIA, MAIS ESPECIFICAMENTE, NO HAI-KAI. NESSE SEMINÁRIO, SE NÃO ME ENGANO, ELE TAMBÉM FALA OUE O MEIO DA VIDA DE ALGUÉM NÃO É CRONOLÓGICO, MAS UM PONTO EM QUE SE ENCONTRA COM UMA ESCRITA

LCB: ... Ou se muda de escrita.

JR: SIM. VOCÊ PODERIA COMENTAR UM POUCO SOBRE ESSA TRANSPOSIÇÃO DO POEMA PARA A NARRATIVA? SE HÁ, AÍ, DE
FATO UMA TRANSPOSIÇÃO... E, SE E UMA ESCRITA O QUE SE ENCONTRA NO MEIO DA VIDA DE UM SUJEITO, NÃO É ESSE MEIO DA VIDA O PRÓPRIO PONTO DA POESIA?

LCB: Essa é uma pergunta super difícil, mas eu me lembro de um momento nesse seminário, no final do volume um, que pode nos levar para próximo dela. Toda discussão, inclusive dos críticos de Barthes, os biógrafos de Barthes, os amigos de Barthes, era esta: o grande desejo de Barthes era escrever um romance. O grande emblema do romance, para ele, é Proust. Então, digamos que Barthes quisesse ser um Proust quando crescesse.

JR: HÁ, INCLUSIVE, AQUELE TEXTO “DURANTE MUITO TEMPO FUI DORMIR CEDO"

LCB: Exatamente. Onde ele conta que o chamaram para falar sobre Proust e ele diz que falará sobre "Proust e eu". E o que eu acho que ele diz disso? Ele diz que o desejo era escrever um romance. Aí, ele resolveu dar um seminário que era o seu próprio desejo - olha o biografema colocado aí! -, A preparação do romance, ou seja, a preparação do romance dele, Roland Barthes. Contudo, ele nunca, classicamente, escreveu um romance. Há quem diga, e eu concordo, que o romance de Roland Barthes é o Fragmentos de um discurso amoroso. E eu acho que ele concordaria com isso.
EM TESE
BELO HORIZONTE
v. 21
N. 2
MAIO-AGO. 2015

CASTELLO BRANCO; ROCHA. Barthes, Lucia e eu: conversa em torno [.. . ]

$213-230$ 
No final do primeiro ano desse curso [A preparação do romance], ele vai batalhando nessa ideia do romance, vai batalhando... vai batalhando... Mas diz assim: "Vamos pensar primeiro na poesia. $\mathrm{O}$ que seria a poesia? A poesia é a forma curta, lembra? A forma condensada, a forma do hai-kai que não tem a ver com a inspiração, mas com uma certa contemplação, o esvaziamento do eu etc." Depois dele ter falado o volume inteiro disso, sei lá quantos meses de aula, ele diz assim: talvez não seja possível passar... Por que a pergunta é esta: "Como passar da forma curta, do poema, à forma longa, do romance?” Ele, então, diz: talvez não seja possível passar da forma curta à forma longa... Talvez, haja aí um impedimento moral... E o impedimento moral é: aceitar a narrativ é aceitar aquela mentira, ou seja, a mentira ficcional que a poesia não aceita. Ele fala isso, João, e é maravilhoso. E esse momento, como você disse, é o meio de uma vida... Nesse seminário, que não chegou ao fim porque Barthes foi atropelado - esse é seu último seminário -, ele começa falando sobre o meio de uma vida e morre mesmo, ali, literalmente. Mas, se nós pensarmos aquele seminário como um todo, pensando que a tarefa de um escritor é sempre mais longa que a sua própria vida, então, o seminário não acabou, ele foi acabado.

Aquele momento em que Barthes chega à formulação de que há um impedimento moral na passagem do poema para a narrativa, eu diria um impedimento ético, é o meio de uma vida. Ali que é o meio de uma vida, entende? Porque ele podia acabar ali o seminário, dizer que então não dá... Acabou. . Eu estou querendo preparar um romance e cheguei à conclusão de que o meu romance vai ser o Fragmentos de um discurso amoroso... Porque eu gosto do fragmento (ele já falou isto em entrevista: "Eu gosto de começar mas eu gosto de terminar também”)... Então, é do fragmento que ele gosta... Começou, terminou, começou, terminou (risos). Entretanto, ele continua, no volume dois, portanto, no outro ano, falando do romance. Nesse momento, aquele seminário é outra coisa. Já não é mais o meu romance, entendeu? É o romance do outro. Aquele que ele não alcançará, porque ele tinha um impedimento ético que o impedia de alcançar isso.

Barthes é aquele sujeito que consegue falar isso, o que é fenomenal (e, nesse ponto, ele é um sujeito mais radical que Blanchot), em primeira pessoa. Em primeira pessoa e na radicalidade do je est un autre, do Rimbaud. Mas ele assume essa primeira pessoa como professor, como escritor... Quer dizer, ele não usa, em momento algum, o truque ficcional.

\section{JR: ELE CONSEGUE MANTER ESSA DISTÂNCIA...}

LCB: "Distante como a palma da mão" ... Ele consegue. E isso é de uma sutileza, de uma delicadeza, de uma beleza! Eu imagino, por exemplo, que Foucault, um grande filósofo,
6. LLANSOL, Maria Gabriela. Hölder, de Hölderlin. Lisboa: Colares editora, 1993. 
7. O livro Maurice Blanchot, organizado por Lucia Castello Sérgio Antonio Silva, é resultado Sergio Antonio Silva, é resultado das leituras realizadas por esse grupo. um grande militante, um grande pensador, mas que não é, necessariamente, um grande escritor, não partilhe dessa delicadeza, porque essa é uma delicadeza de escritor, e Foucault, talvez, não compreendesse isso muito bem.

JR: LUCIA, QUANDO VOCÊ FALA SOBRE ESSA DELICADEZA DE UM ESCRITOR COMO BARTHES, OUE SE CONTRAPÕE, EM UMA CERTA MEDIDA, À MILITÂNCIA COBRADA POR UM FOUCAULT, POR EXEMPLO, EU ME LEMBREI DESTAS DUAS PASSAGENS DO LIVRO INCIDENTES: "ABDER - QUER UMA TOALHA LIMPA OUE, POR TEMOR RELIGIOSO DA SUJEIRA, É PRECISO COLOCAR ALI, AO LADO, PARA SE PURIFICAR MAIS TARDE DO AMOR". E: "ALIWA (BONITO NOME PARA REPETIR INCANSAVELMENTE) GOSTA DE CALÇAS BRANCAS IMACULADAS (NO FIM DA ESTAÇÃO), MAS, EM VISTA DO DESCONFORTO DOS LUGARES, NESSE BRANCO DE LEITE SEMPRE VEIO COLOCAR-SE UMA MANCHA". A IMPRESSÃO QUE EU TENHO DE BARTHES É OUE ELE ESCREVE NO PONTO DESSAS PEQUENAS MÁCULAS. MÁCULAS DO AMOR, EM UMA TOALHA; MÁCULAS DO PERCURSO DE UM SUJEITO, EM SUAS CALÇAS BRANCAS, COMO O LEITE. NÃO É NECESSÁRIO EXPLICITAR... EXPLICITAR NO SENTIDO DO OBSCENO, QUERO DIZER... BARTHES NÃO É OBSCENO...

LCB: Não... nunca... jamais. Nesse ponto, eu acho que ele se parece com Blanchot, porque Blanchot também não é. Eu adoro o Blanchot pensador, filósofo, teórico da literatura, mas o Blanchot do récit nem sempre eu o acho tão despojado, digamos assim, quanto Barthes. E olha que nós lemos muito, nós ficamos sete anos lendo Blanchot naquele grupo ${ }^{7}$. Barthes é despojado e, nesse sentido, ele é mais contemporâneo, entende? Blanchot, de vez em quando, parte para esse grande mistério da ficção, digamos assim. Ele é despojado no Instante da minha morte, mas, por exemplo, no Pena de morte, ele não é tão despojado.

\section{JR: NEM NO THOMAS L'OBSCUR.}

LCB: Nem no Celui qui ne maccompagnait pas, nem em La folie $d u$ jour, que também é um livro bacana, entende? Há alguma coisa do grande romance, por mais que seja um récit, por mais que ele tenha "emagrecido" isso ao ponto do récit, entendeu? Ele cede um pouco a essa tentação. Barthes não cede.

JR: NESSE PONTO, EU VOU RETOMAR UMA PALAVRA OUE VOCE DISSE NO COMEÇO DESTA CONVERSA E QUE ME INOUIETOU UM POUCO. A PALAVRA É "NOBREZA". BLANCHOT TEM UMA CERTA NOBREZA, UM OUTRO TIPO DE NOBREZA... UMA NOBREZA DO ARTIFICIO...

LCB: ... Um artifício muito bem colocado.

JR: E BARTHES, NESSE PONTO QUE VOCÊ MARCA COMO UM DESPOJAMENTO, TEM UMA CERTA POBREZA... NÃO É À TOA OUE ELE ERA LIVRO DE CABECEIRA DA LLANSOL...

LCB: Isso... Pobreza... No sentido do despojamento.. E todo mundo que conheceu Barthes, seguiu seus seminários, fala que o que mais comovia nas suas aulas, na
EM TESE
BELO HORIZONTE
v. 21
N. 2
MAIO-AGO. 2015

CASTELLO BRANCO; ROCHA. Barthes, Lucia e eu: conversa em torno [.. .

$213-230$ 
presença dele, eram duas coisas: o quanto ele era discreto e a delicadeza. Dizem que Barthes era de uma delicadeza impressionante. Quando ele se dirigia ao outro... Quando ele escutava... Isso é muito legal, não é? Pensar que um cara consegue falar para uma pequena multidão nesse ponto. O que não era, absolutamente, o caso de Lacan (risos). Lacan não tem nada de delicado (risos). Ele é engraçado.. doido... Mas delicado, não. E Barthes conseguiu manter aquilo tudo no ponto do sujeito discreto e da delicadeza. Isso é muito interessante, não é, João? Eu sempre falo com os alunos, quando vão dar alguma aula e ficam tímidos, você já deve ter ouvido isso, que este é o sentido de uma aula expositiva: quem se expõe é o professor. Se há uma coisa que acontece com o professor, ali, quando ele vai tomando certa intimidade com uma turma, é uma exposição. E ele, Barthes, nunca resvala na exposição... Ele tem uma elegância... E uma delicadeza... Isso é impressionante! $\mathrm{E}$ eu acho que o texto dele é isso. Você pega lá o Incidentes, por exemplo. Todo mundo, depois de Roland Barthes par Roland Barthes, esperando que, finalmente, nesse livro de memórias de Barthes, ele contaria tudo. E conta, mas daquele jeito. Não resvala nada. Todo mundo sabe o que ele ia fazer no Marrocos, com quem ele ia encontrar... Mas não resvala. Blanchot também tem isso, mas à custa de um certo mistério que ele cria no próprio texto e também em torno da sua figura. Barthes é sem mistério.
JR: NESSA AURA DE MISTERIO OUE ENVOLVE A FIGURA DE BLANCHOT, É COMO SE ELE TIVESSE QUE FAZER MUITO ESFORÇO PARA ISSO... PARA NÃO SE EXPOR.

LCB: Exatamente. Barthes parece que já tinha esse ponto um pouco opaco...

JR: QUANDO VOCÊ LEMBRA DE A PREPARAÇÃO DO ROMANCE, DESSA PASSAGEM DO POEMA PARA O ROMANCE, DO IMPEDIMENTO MORAL QUE AÍ RESIDE... IMPEDIMENTO ÉTICO, COMO VOCÊ COLOCA...

LCB: ... Se a gente falasse em linguagem llansoliana, diríamos da narratividade à textualidade... Não tem como haver essa passagem... Não tem.

JR: É. POR ISSO, AGORA, UMA PERGUNTA SOBRE ALUCIA, EM PONTO DE BIOGRAFEMA. HÁ A SEGUINTE QUESTÃO PARA ROLAND BARTHES: "COMO VIVER JUNTO?". QUESTÃO LEVANTADA POR ELE E MUITO ATUAL, TENDO EM VISTA O MUNDO QUE NÓS CONSTRUIIMOS...

LCB: Você já leu esse seminário?

JR: NÃO LI TODO...

LCB: Eu tenho. Nunca consegui lê-lo inteiro... Engraçado... Esse seminário me interessa tanto... Ele fala das beguinas! Eu sempre vou nele, mas não consigo acompanhá-lo... Talvez por ele ser muito histórico, muito cheio de dados sobre as experiências de comunidade... 
JR: TALVEZ, PELO FATO DE BARTHES DEMORAR NO PONTO DO FRAGMENTO, DA POESIA, A OUESTÃO “COMO VIVER JUNTO?" SE TORNA MUITO INTERESSANTE...

\section{LCB: Demais}

JR: E ESSA QUESTÃO SE COLOCA AQUI POROUE VOCÊ COORDENA JUNTO COMO OUTROS ESCRITORES E PSICANALISTAS, UM ESPA CO, A CAS'A'SCREVER, OU SEJA, UMA CASA. PORTANTO, TEMOS AÍ VOCÊ E MAIS OUTROS.

LCB: E mesmo os outros da casa, não são somente aqueles que trabalham ali dentro. Você, por exemplo, é um outro da casa. Você não trabalha ali dentro, mas trabalha. Vem aqui, participa de grupos de estudo..

\section{JR: EXATAMENTE.}

LCB: Mas você não mantém a casa... Não ganha dinheiro na casa... Nada disso. Mas desde a fundação desta casa, voce esteve presente. Pintou parede... (risos). Várias coisas que fizemos aqui, você estava presente... Quer dizer, você faz parte da casa. Você frequenta a casa... Do mesmo jeito que a Lia [Krucken]... Ela estava em Amsterdã e foi ser apresentada ao pessoal do ICORN... "E você, quem é?"... E ela falou assim: "Eu faço parte da Cas'a’screver". Porque ela faz tanta coisa na cas'a... Você também! Ela fez o site da cas'a, ela fez cartaz da cas'a... Entendeu?
JR: EU ACHO MESMO OUE ESTE ESPAÇO, PRINCIPALMENTE COM ESTA SALA EM OUE ESTAMOS, CHAMADA (PAUSA)LER, OUE ABRIGARÁ SEMINÁRIOS

LCB: Esta sala que é dentro e fora da casa...

JR: ISSO. E TAMBÉM, AGORA, COM O SEU TRABALHO DE ABRIGO, JUNTO À CABRA ${ }^{8}$ E AO ICORN ${ }^{9}$, A ESCRITORES EXILADOS... EU ACHO MESMO QUE HÁ UM PONTO, AÍ, ÉTICO, QUE TEM A VER COM A LITERATURA E TAMBÉM COM A PSICANÁLISE, OUE É DE UMA ABERTURA PARA O ENCONTRO. NÃO DÁ PARA FALAR, POR EXEMPLO, QUE A CAS'A'SCREVER É SOMENTE UM CONSULTÓRIO OU SOMENTE UMA ESCOLA..

LCB: ... E, no entanto, poder ser um pouco disso tudo.

JR: COMO UMA CASA É UM POUCO DISSO TUDO.

LCB: Quando a gente viu o site do Instituto $17^{10}$, dirigido pelo Benjamín Mayer Foulkes, o que mais me interessou foi a chamada que diz assim: uma casa de escrita, psicanálise e cultura não acadêmica. Isso de cultura não acadêmica é bom demais, não é? É cultura não acadêmica nesse sentido do Barthes, entendeu? Uma cultura não acadêmica que não virou academia, mas cursos livres com diploma, reconhecidos pelo governo como faculdade! Aquilo lá é uma faculdade que Benjamín criou, você sabia? Eu não sei bem como é o caminho para isso, mas a Ângela [Castello Branco] e o Giuliano [Tierno], lá em São Paulo, nessa casa que eles abriram, a
8. Sobre a CABRA, Casas Brasileiras de Refúgio, segue o link: https:// cabrarede.wordpress.com/.

9. Sobre o ICORN, International Cities of Refuge Network, segue o link: http://icorn.org/.

10. Sobre o Instituto 17 , segue o link: http://17edu.org// 
Casa Tombada ${ }^{11}$, já receberam uma autorização de uma universidade que tem um nome muito bacana, Universidade das Conchas, para poderem dar o curso que quiserem, naquela casa, e esses cursos são cursos reconhecidos por essa universidade, entendeu? Então, eu fico pensando assim: "Por que não? Por que a gente não pode fundar, aqui, alguma coisa que possa ser, daqui a alguns anos, meio Collège de France?" Nós todos não somos pessoas estudiosas, dedicadas, carregamos piano... não é? Então, por que não?

Sábado, nós fizemos o lançamento do livro do Paulo de Andrade e a Sônia Queiroz venho aqui e está querendo dar uma palestra... Daisy Turrer veio e está querendo dar um seminário aqui... Ione de Medeiros disse que quer conhecer a cas'a e colocá-la no VAC [Verão Arte Contemporânea] e eu acho muito legal, porque uma coisa é a universidade e outra é a intervenção na cidade. Porque tem isto também: casa como uma intervenção na cidade. O que eu acho sensacional. Isso não prejudica os consultórios, porque eles estão lá do outro lado da casa, então esse trabalho continua.

Nós vamos conseguir trazer, para a universidade, com a ajuda da Sylvie [Debs], dois refugiados que vão para o Fórum das Letras de Ouro Preto e depois para a Faculdade de Letras da UFMG para um encontro, de um dia, sobre os temas: a escrita, o exílio, a casa. Sylvie me disse que eles ficariam um pouco perdidos em Ouro Preto, porque vão ficar quatro dias lá... Eles falarão em suas mesas, mas não falam português... Então, não conseguirão ver quase nada... Ela me disse, então: "Você não quer trazê-los para passear um dia aqui em Belo Horizonte e para eles conhecerem a Cas'a'screver?" Então, nós vamos fazer um dia com a Safaa Fathy e o Girma Fantaye aqui, na Cas'a'screver. Outro plano era trazer o Benjamín [Mayer Foulkes], mas hoje ele me disse que não conseguirá vir a Belo Horizonte, então nós vamos fazer esse encontro na Casa Tombada, em São Paulo. Outro plano, para continuar os seminários que estão acontecendo aqui - eu espero que vocês também continuem - é convidar alguém para abrir esses seminários, para falar a partir do tema "Eu leio assim este texto" e já sei até sobre qual livro será. Adivinha quem é? Eduardo Vidal.

\section{JR: E QUAL LIVRO SERÁ}

LCB: Um livro que Paloma Vidal acabou de traduzir chamado O livro dos divãs, da Tamara Kamenszain, uma escritora argentina. Um livro só de poemas sobre as experiências dela de psicanálise... Dos divãs... As várias análises que ela já fez. Eu já li um livro dela chamado O eco de minha mãe que fala da mãe doente com Alzheimer... E agora ela fez esse Livro dos divãs. . Eu queria que Vidal topasse falar sobre esse livro, porque a gente tem pensado muito nisto: o que seria a narrativa acerca da clínica sem ser feita por um analista, mas por outra pessoa,
EM TESE
BELO HORIZONTE
ง. 21
N. 2
MAIO-AGO. 2015

CASTELLO BRANCO; ROCHA. Barthes, Lucia e eu: conversa em torno [...

$213-230$ 
no caso, um poeta. Não é legal? Eu acho que isso tem a ver com Barthes, pois ele tinha algo de um deslocamento, porque essa, eu acho, é a palavra mais legal para pensar Barthes. Algum crítico dele, acho que é a Leyla Perrone mesmo, vai dizer que ele ensina a gente a lição do abjurar. Quando você pensa que ele está aqui ele já passou para outro lugar. Não sei se eu chamaria isso de abjurar, porque o abjurar tem algo de um certo desprezo pelo o que já se fez e eu não acho que é isso. Eu chamaria de deslocamento. Primeiro, porque há um movimento do sujeito que escreve e, para ele se deslocar para a sala de aula, por exemplo, já é outro movimento. Depois, você se deslocar de novo para a escrita é outro movimento. Uma coisa é a universidade, outra coisa é o Collège de France, não é? São deslocamentos. Deslocamentos que, por exemplo, Blanchot, talvez, por sua própria condição física, ele era muito doente, não conseguiu muito fazer. Blanchot não conseguiria eu acho, fazer esses deslocamentos.

\section{JR: A LLANSOL TAMBÉM FEZ, NÃO É?}

LCB: A Llansol também fez. Ela saiu de Portugal, foi para Bélgica, viveu vinte anos lá, aprendeu outra língua, fundou uma escola, essa escola também se deslocou para outro lugar, depois ela volta para Portugal. Digamos que, com toda reclusão da Llansol, ela conseguiu fazer esses deslocamentos. E, depois, ela fez muitos no final da vida. Ela não só começa a fazê-los, quando é reconhecida como escritora, pois ela não se nega a esse lugar, e vai, faz discursos, depois faz os colóquios, participa dos colóquios, pensa nos colóquios, escolhe como as coisas iam ser feitas... Isso tem a ver com um certo estar no mundo. E talvez com isso que você fala da comunidade. Se for impossível fazer a comunidade, o desejo de comunidade, de algum jeito, está aí. Mesmo que ela seja impossível, isso não nos impede de desejá-la. A comunidade é sempre a comunidade por vir.

JR: E O MAIS INTERESSANTE É COMO ESSA CONVERSA FOI TOMANDO O RUMO PARA O LUGAR DO PROFESSOR E EU ACHEI ISSO MUITO BOM. VOCE DISSE, LEMBRANDO DO PETER PAL-PELBART, QUE A FUNÇ̃̃O DO PROFESSOR É FAZER O ALUNO SE RECONCILIAR COM SUA PRÓPRIA SOLIDÃO, E ESSE É O MOVIMENTO DE UMA COMUNIDADE..

LCB:... Esse é o movimento de uma psicanálise...

JR: ... DE UMA COMUNIDADE QUE NÃO É PAUTADA NAS SEMELHANÇAS...

LCB: ... Nas simbioses. .

JR: ... HÁ TAMBÉM AÍ UM DESLOCAMENTO DO PRÓPRIO DISCURSO ACADÊMICO... POR ISSO, TALVEZ VOCÊ CITE ESSAS DIFICULDADES DOS DESLOCAMENTOS DO PROFESSOR PARA O ESCRITOR E VICE-VERSA... 
LCB: ... Tudo isso dá muito trabalho... Dá muito trabalho construir isso. Eu entrei para a Faculdade de Letras, brigando com a Universidade, com mandato de segurança etc. Nunca achei que não valeu a pena ter feito isso. Eu podia ter pensado: "Poxa, eu briguei por esse lugar e o que estou fazendo aqui?" Mas, não. Sempre achei que, quando eu pudesse me aposentar, eu me aposentaria no dia seguinte e não ia querer saber de dar aula. Eu posso até me aposentar rápido, mas sempre vou querer saber de dar aula. Então, isso já é uma coisa impressionante para quem chorava quando ia dar aula, não é? Para quem achava que aquilo ali não podia ser o seu destino... E muito do que eu conquiste foi exatamente a universidade que me deu. Por isso que eu fico muito indignada quando eu ouço coisas do tipo: "A universidade, porque a universidade, porque a universidade!" Mesmo nessa rigidez que é a academia, ou talvez pela rigidez mesmo que é a academia, ela possibilita os seus deslocamentos. A universidade pública, João. Eu não acredito em nenhuma outra mais. Não acho que possa haver nenhuma outra. Hoje em dia, eu vejo uma certa resistência em se tornar universitário. Há o discurso universitário da psicanálise... Há essa visão de que se você se tornou universitário, você se tornou claro, sem poesia... E, pela minha experiência de trinta anos na universidade, sempre achei que ela, cada vez mais eu acho isso, é muito menos o universal e mais o universo. A universidade pública. Tem de tudo dentro da universidade. E, se tem uma coisa que a universidade sabe reconhecer, com toda a dificuldade, são as pessoas geniais (risos). Porque tem gente muito genial dentro da universidade. Senão, ela não existiria, entendeu? Seriam só os medíocres, o saber acadêmico, aquela espécie de bestialização e normatização. Mas não tem só isso. Tem isso também, porque ela é tão diferente que é diferente de si mesma. Mas tem as figuras muito geniais, até no sentido mais de loucas, que a universidade, com todo o seu esquema normatizante, não consegue barrar que entrem em um concurso. Por que será? Então, mesmo Barthes não sendo um universitário, no sentido de uma formação, eu não acho que ele desprezaria a universidade.

Tem alguma coisa que a universidade te dá, João, que só ela consegue te dar. Isso é muito doido também... E o que eu acho mais admirável é que Barthes, não sendo um universitário de formação, tem isso. Esse rigor, essa precisão, essa pesquisa... Aquele negócio do caderno, João, que ele ia dar aula... Todo lindo... O manuscrito dele.. Porque ele era também um artista plástico, vamos dizer.. Sabe essa coisa do caderno do professor? Hoje eu faço isso com o maior apreço... Para qualquer curso que eu vou dar e acho importante... Eu faço um caderno... Vou bordando... Mas é preciso chegar nesse nível de sutileza para sacar o que é isso.
EM TESE
BELO HORIZONTE
v. 21
N. 2
MAO-AGO. 2015

CASTELLO BRANCO; ROCHA. Barthes, Lucia e eu: conversa em torno [... $]$

P. 213-230 
JR: E PARA SACAR TAMBEM UMA COISA QUE EU ACHO DIFICIL: ESSE PONTO IRRECONCILIÁVEL QUE É A UNIVERSIDADE. QUANDO VOCÊ FALA DA UNIVERSIDADE COMO O UNIVERSO, EU ENTENDO QUE HÁ ALGO AÍ EM EXPANSÃO, JÁ QUE O UNIVERSO ESTÁ EM EXPANSÃO, MAS, NESSE MOVIMENTO, TAMBÉM HÁ UM ENRIJECIMENTO... ENRIJECIMENTO E ABERTURA... ESSAS DUAS COISAS QUE NÃO SE RECONCILIAM, TEORICAMENTE, MAS VIVEM EM TENSÃO.

LCB: Por exemplo: se a gente conseguir, de fato, fazer com que a primeira casa de escritor refugiado, no Brasil, ligada a essa ONG que é o ICORN, que tem dez anos, quarenta e tantas casas espalhadas pelo mundo, todas casas-refúgio, em cidades refúgio... Se a gente conseguir que a cidade-refúgio, no Brasil, não seja exatamente a cidade-refúgio, mas a universidade-refúgio... Isso não é de um avanço impressionante para a universidade? Porque, se isso der certo aqui em Belo Horizonte, na UFMG, isso vai virar modelo para o Brasil. Então, no Brasil, que é muito grande, não serão, exatamente, as prefeituras as cidades-refúgio, mas as universidades. Tive uma reunião com a Graciela [diretora da Faculdade de letras da UFMG], e estava lá a Tereza Virgínia, coordenadora do CENEX. Tereza, por causa da coordenação do CENEX e porque o seu bairro foi invadido por refugiados sírios (o mesmo bairro em que um padre alojou, dentro da sua casa, quarenta refugiados), descobriu, frequentando esse grupo, que há ali professores, médicos... Sabe o que ela vai fazer? Vai abrir um edital para esse pessoal poder dar aula de árabe no CENEX, da Letras. Nesse dia, eu fiquei emocionada com isso. Descobri que há uma portaria da UFMG para receber alunos refugiados e, portanto, ela é uma das universidades, no Brasil, que dá abrigo a esses alunos.

Junto com esse discurso de que a universidade virou uma coisa careta... De que todos nós temos que ficar prestando conta para a CAPES... ao CNPQ... Quando vem esse discurso, junto com ele também vem isto: "Então é melhor privatizar..." Porque isso tudo é a universidade pública. Então vamos pensar de outro jeito... Vamos acabar com as bolsas, se ninguém quer prestar conta de nada... E, na hora em que isso acontecer, acabou a universidade. Você tem essa experiência de dar aula na rede privada e sabe o que é isso... Pergunta à Janaina [Rocha de Paula] que dá aula há anos em faculdade particular... Ela está dando aula, agora na Letras, e está rindo daqui até aqui... Ela falou, ontem, que saiu da aula tão emocionada que falou assim: "Já sei. Eu vou casar com a Letras. Não vou querer mais casar com ninguém, eu quero é casar com a Letras. Essa que vai ser a minha vida" (risos). Ela está assim... dando aula, numa alegria! Eu acho que ela está vendo a diferença, pois ela já dá aula há anos. Ela começou como professora primária deu aula em escola particular, em cursos de formação de psicanálise... 
JR: EU ACHO MESMO QUE O ÚNICO LUGAR, NO CAMPO DA EDUCAÇ̃̃O, EM QUE SE PODE MUDAR ALGUMA COISA É AQUI, NA ESCOLA PÚBLICA.

LCB: Porque no resto você vai só repetir o padrão da aura mediocritas, como diria o Sebastião Nunes, da classe média, de uma certa aristocracia, dependendo da escola. Então, eu fico maravilhada de pensar que um cara como Barthes, que não é rigorosamente um universitário, mas que é rigorosamente um pesquisador, consiga ter se tornado o professor e o escritor que ele é. E o leitor, não é, João? Mais ainda do que crítico, o leitor que ele é. Penso que, se o que reúne isso tudo do Barthes, não é esse significante que ele abandonou, porque ele precisava abandonar, para mostrar que a literatura não está só na literatura, ela está naquilo que a Shoshana [Felman] chama de "coisa literária", que extrapola a literatura e muito, mas ao qual ele retorna, justo no momento em que ele vai dar aula no Collège de France... Era importante ele erigir à dignidade da coisa esse objeto, que é a literatura. Por isso, eu acho maravilhoso pensar na Aula como um livro inaugural... Ou talvez final. 